\title{
TOWARDS A NEW CONCEPTUAL FRAMEWORK OF E-MAINTENANCE
}

\author{
D. Vasiljevic ${ }^{1} \&$ B. Cvetic ${ }^{2}$ \\ ${ }^{1,2}$ Faculty of Organizational Sciences \\ University of Belgrade, Serbia \\ ${ }^{1}$ vasilj evic@fon.bg.ac.rs, ${ }^{2}$ cvetic@fon.bg.ac.rs
}

\begin{abstract}
The aim of this paper is to design a conceptual framework of e-maintenance based on a hybrid system approach, and to analyse its characteristics and the effects of the system on maintenance and business performances. The Interactive Electronic Technical Manual is recognized as an effective e-learning tool and the main maintenance-related component of the framework. The major benefits of the developed framework are an automated process of data entry, maintenance of data consistency, decreased data redundancy, and customised reporting. The proposed conceptual framework should be suitable for maintenance and logistics engineers who intend to develop e-maintenance in industrial sites.
\end{abstract}

\section{OPSOMMING}

Die doelwit van hierdie artikel is om 'n konseptuele raamwerk vir e-instandhouding gebaseer op ' $n$ hibriede stelselbenadering te ontwerp. Daarna word die eienskape van die stelsel ontleed asook die effek daarvan op instandhouding en ondernemingsprestasie. Die interaktiewe elektroniese tegniese handleiding is ' $n$ erkende hulpmiddel e-leerhulpmiddel. Die belangrikste voordele van die ontwikkelde raamwerk behels ' $n$ geoutomatiseerde proses vir datavaslegging, die byhou van data, verminderde data-oortolligheid en doelgemaakte verslagdoening. Die voorgestelde konseptuele raamwerk is toepaslik vir instandhoudings- en logistieke ingenieurs wat e-instandhouding wil ontwikkel vir industriële toepassings. 


\section{INTRODUCTION}

Globalisation and individualised customer demands are the main challenges facing modern enterprises. Logistics has a critical role to play in meeting these challenges. The premise of this paper is that there will be no improvement in logistics unless there is an improvement in the area of maintenance. As a result, the raison d'être of maintenance has been reevaluated. A reactive 'fire-fighting' approach to maintenance tasks has been replaced with a proactive and reliable process, ensuring better maintenance performance. Proactivity in maintenance (degradation-based anticipation) has become crucial in avoiding negative influences on product conditions. Proactivity in maintenance requires an e-maintenance philosophy to emerge in order to support the transformation from 'fire-fighting' maintenance practice to 'predict and prevent' strategies (e.g. [1, 2]).

For many companies, maintenance is the largest controllable cost within an operating system. The aim for these companies should be to transform their maintenance process into a proactive e-environment. Many approaches, methods, and tools that support maintenance performance growth have recently emerged around the world. However, the maintenance improvement programme had to be integrated with broader corporate improvement programmes [3]. The concept of Life Cycle Integration ( $\mathrm{LCl}$ ) provides a broader logistic look into inter-organisational relations. According to Rakita \& Chromjakova [4], LCl provides the basis for conceptualising an integrated information flow matched to engineering and business settings.

E-maintenance is a sub-system of e-manufacturing or e-business in the form of an information network that integrates various concepts, applications, and tools. These in turn monitor, gather, and deliver asset information in the right format, at the right time, and in the right place. E-maintenance ensures information flow in real time and is independent of geographical location. It is the consequence of two major trends in modern society: the growing importance of maintenance, and the rapid development of information and communication technology.

The paper is organised as follows. In Section 2 we provide theoretical background information. In Section 3 we analyse the system basics of maintenance performance improvement. In Section 4 we propose a conceptual framework of e-maintenance based on a hybrid system approach, and point out the importance of the Interactive Electronic Technical Manual. We end with a discussion and conclusion in sections 5 and 6 respectively.

\section{THEORETICAL BACKGROUND}

In the past, various strategies within an enterprise - such as marketing, operations, and maintenance - were not always integrated, and they rarely focused on customers. Formal maintenance operations were usually inadequately planned and tracked due to poor communication. A number of new technologies and methods are available to provide information about the condition and performance of equipment. The key disadvantage of most of these technologies is that they fail to integrate their information with the information from other technologies; so what information is available to industrial and maintenance engineers often causes suboptimal decision-making. This sometimes occurs because many enterprises use management information systems developed years ago in a very different environment [5].

In recent years, many companies have collected and kept an enormous amount of data, much of which has been unusable or has never been used. In many companies information has been treated as the exclusive responsibility of the management information systems department. For a long time, maintenance was viewed as a 'factory within a factory'. Information is produced and used in different enterprises and in different information systems. The need for industry to integrate engineering processes (inclusive maintenance) is becoming increasingly evident. Thus information refinement services are needed to manage information flows in company networks between the different systems [6]. 
There is a trend now towards integrating the maintenance system into the logistics system, although an independent organisational department for maintenance affairs can still exist. Maintenance should be an integral part of logistics and of the comprehensive business strategy. This includes the whole spectrum of activities, from product and support design to the disposal of equipment. According to Vasiljevic \& Popadic [7], a modern logistics system makes it possible to control the store, search, filter, locate, access, view, transfer, update, and manage digitalised engineering and maintenance data, providing a framework for reducing costs. A logistics system, therefore, consists of a complex mix of resources in the form of HR, materials, hardware, software, facilities, and data, which are integrated to meet the requirements of defined customers and stakeholders.

The purpose of current maintenance improvement efforts is to offer a redesign of the maintenance process, thus improving performance dramatically. Maintenance is a unique business process that requires an approach different from other processes if it is to improve successfully [8]. From a maintenance point of view, improved efficiency and effectiveness can be sought by increasing value within an enterprise through the integration of logistics data. The term 'integrated' refers here to "the process of reconciling data from many different sources so that the resulting collection can be managed with minimum redundancy" [9]. Kutucuogly et al. [10] show that the maintenance processes should extend beyond technological improvements to blend more with logistics concepts, and to be in harmony with the mission and vision of the enterprise.

A large amount of literature - and much software - focuses on isolated components of the logistics system. All logistics tasks have an information component; and, since a growing number of parties are involved in those tasks, integrating those components has become essential [11]. The market for software applications is flooded with products designed for maintenance purposes, either 'stand alone' or included in high performance software packages and broader business functionalities. When deciding which software product to use, a wide-ranging analysis is needed that includes: the performance and functionality of the software solution; how easy it is to use; its price; the reputation of the different software companies; compatibility; availability of support and training; cycle time implementation and customisation; and most importantly, integration requirements and possibilities [12].

The platform for maintenance support and improvement could be a Computerized Maintenance Management System (CMMS), an Enterprise Resource Planning (ERP) system, or a comprehensive logistics information system such as LCl. Uniform identification and data exchange is now one of the basic conditions for maintenance and logistic inter-operability. Boyson et al. [13] show that Computer Integrated Logistics (CIL), with its tendency to span functional boundaries, has become the driving force in the effort to create an extended enterprise.

E-maintenance has received significant attention in the past decade with several definitions, frameworks, hardware, and software solutions being developed all over the world. It refers to the maintenance support that includes resources, services, and management-enabling proactive decision-process execution [14]. The ' $\mathrm{e}$ ' in e-maintenance means excellent, efficient, and effective enterprise maintenance (with a direct contribution to enterprise performance) according to Baldwin [15]. A framework for an emaintenance system has been analysed in Holmerg et al. [16], Verma et al. [17], Lung et al. [18], Muller et al. [19], and Han \& Yang [20]. Several e-maintenance platforms have been developed. The best known are PROTEUS, QEUSTRA, ICAS, DYNAWeb, ENIGMA, TELMA, DEXTER, DIAMOND, and SEMATECH. These platforms mostly support condition-based maintenance, to which access to remote functions using 'the web' is added. Only a few of them are fully in line with global e-maintenance requirements [21].

The actual paradigms of maintenance are customisation, sustainability, and collaboration. In this context, e-maintenance offers customised support and logistics solutions to all stakeholders, on demand, in real time, 24 hours a day, and seven days a week. As the 
manufacturing paradigm shifts towards supporting a sustainable society, the role of maintenance has to change to take into account a life cycle management-oriented approach [22]. Finally, collaboration allows sharing - not only of data but also of knowledge and e-intelligence - between all the stakeholders and throughout the product life cycle. It implies the need to develop a new e-maintenance framework to support actual maintenance paradigms.

\section{THE SYSTEM BASICS OF MAINTENANCE IMPROVEMENT}

Two contrasting system approaches can be used for business process improvement, according to Carlisle \& McMillan [23]:

1. Newtonian-Cartesian

2. Complex Adaptive.

The Newtonian-Cartesian approach (illustrated in Figure 1) looks at a system as a machine that can be decomposed into subsystems. The system structure is viewed as hierarchical similar to an organisational chart. This decomposition allows more manageable and continuous improvement of the subsystems. There is a general rule: if each subsystem improves its performance, then the overall system is believed to improve. The main disadvantage of this approach is its unsuitability in dealing with systems with a high level of complexity.

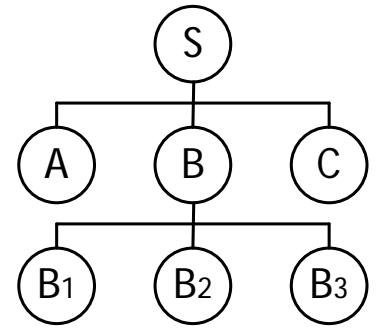

\section{Figure 1: Newtonian-Cartesian approach}

The Complex Adaptive approach depicts the enterprise as a living system, with many interrelationships between components, as shown in Figure 2. The structure of the system is heterarchical, where influence rather than control is communicated to other components. In this approach, each component has autonomous decision-making capabilities. It improves by becoming more flexible and adaptable to unpredictable changes in the enterprise environment. The advantage of this approach is that it leads to a more flexible system, and it anticipates the effect of changes in one component on the overall system performance. The main disadvantage of the Complex Adaptive approach is that the system often fails to achieve optimal global performance because each component tends to be driven to a local optimum.

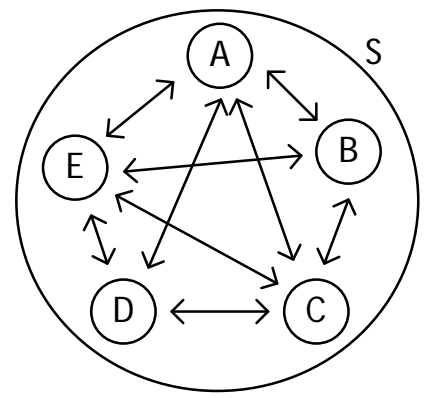

Figure 2: Complex Adaptive approach

From a maintenance point of view, processes of change are not exclusive. It is possible to make continuous past-based maintenance changes in accordance with some discontinuous, future-based change. In this paper we will use the term 'hybrid transformation'. The 
maintenance hybrid transformation balances the system performance between global optimal solutions and robust performance. As illustrated in Figure 2, the number of interfaces between components grows as $n(n-1)$, where $n$ is the number of components. If we use a common data model (see Figure 3 ), the number of interfaces only grows as $2 \mathrm{n}$. In this sense, a data model is a formal description of the data required for the life cycle support of technical systems. It is the platform for interoperable information, and can be implemented in a variety of databases (relational, object-oriented, etc.) [24]. Thus the maintenance improvement model using holonic principles has been facilitated by an improvement in information systems.

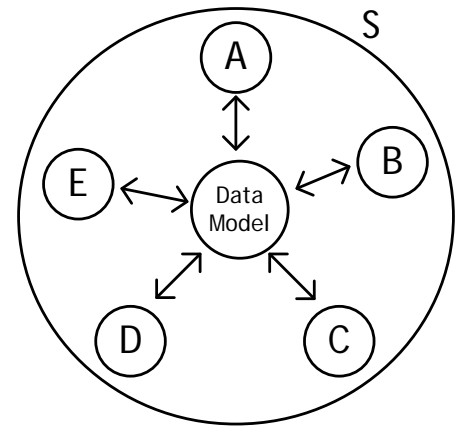

Figure 3: Hybrid approach

\section{THE FRAMEWORK OF E-MAINTENANCE}

A data model defines a common set of data definitions and structures to support emaintenance throughout the system life cycle. Responsibility for planning, generating, collecting, and compiling maintenance data should not belong only to the maintenance department. It should be an inter-functional task with leaders from both maintenance engineering and information department staff. Because engineering applications - such as computer-aided design, computer-aided engineering, computer-aided manufacturing, computer-aided planning, etc. (broadly termed 'computer-aided technologies' or CAx) manipulate simulations of the real world, they present semantically and structurally very complex information models. In non-integrated operating systems, each primary application data change, usually using a computer-aided design (CAD) system, provokes additional activities for other application updates. Consequently, the designers, manufacturers, and maintainers do not have control over the product databases. To overcome these problems, there is a need to integrate engineering processes within an integrated product-service database.

The significant part of the database is product information that has been gathered throughout the life cycle of the product. This covers the design, development, manufacture, maintenance, modernisation, and disposal phases of the product. The database should be three-dimensional and include information on the product type (manufacturer, bill of material, work conditions, standard maintenance procedures); product (name, maintenance history); and location.

The new e-maintenance framework based on the hybrid system approach (see Figure 4) is developed to coordinate maintenance and logistic data, shared between different stakeholders throughout the life cycle of the system. The main pillars of the framework are:

1. Automated data collection;

2. Supportability analysis;

3. Concurrent engineering;

4. Electronic data interchange; and

5. Interactive Electronic Technical Manual. 
Computers automate many aspects of maintenance operations, usually relying on keyboard input and paper output. However, there are situations where the entry and reporting of maintenance data can be automated. Automatic data collection (ADC) is the process of automating the entry and dissemination of digital information. It is an assortment of technologies that provide an alternative to keyboard entry. ADC includes radio frequency identification (RFID), touch memory, pen-based monitors, voice recognition, etc. Worldwide, RFID tagging is growing by $30 \%$ annually, according to research by Allied Business Intelligence [25]. ADC may be considered a tool to manage the generation, storage, updating, and reproduction of technical and business data. Data modes that may be shared under $A D C$ are drawings and design, planning and resources, project management, logistical support, and financial and commercial data.

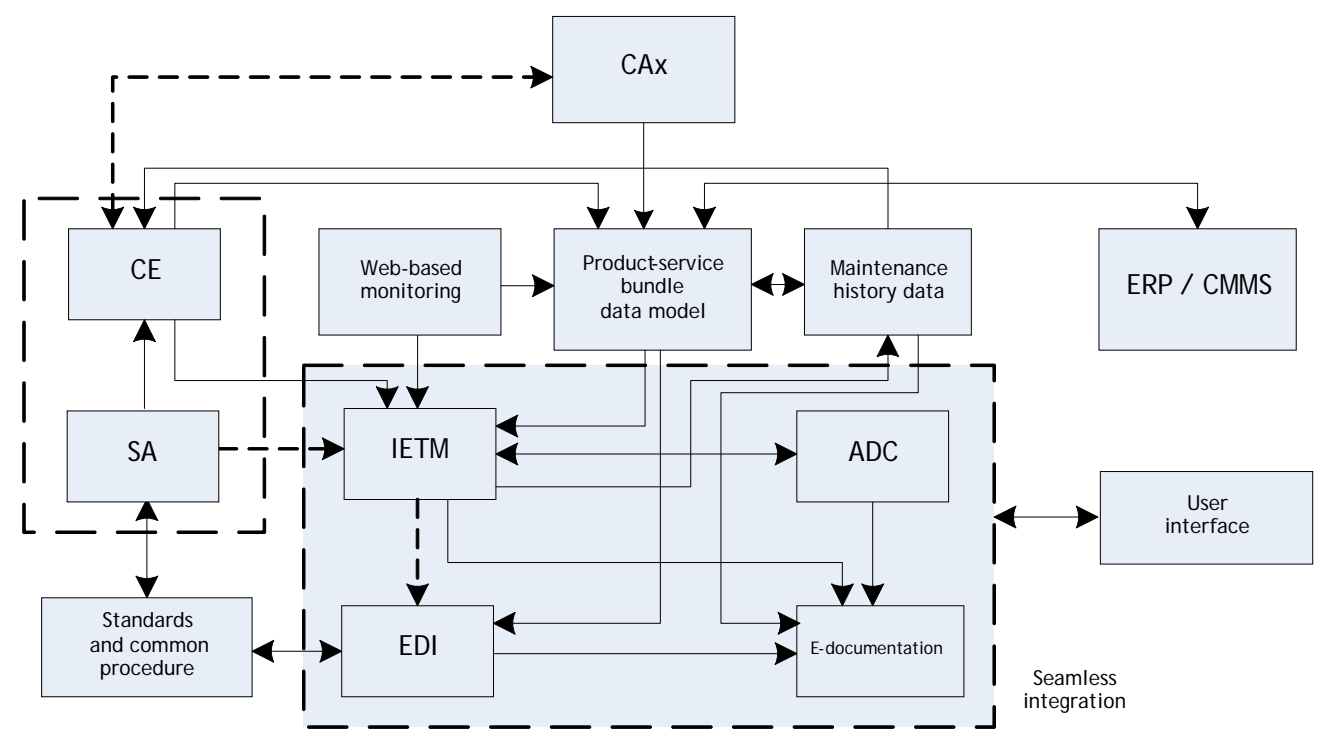

Figure 4: Structure of e-maintenance framework

Supportability analysis (SA) is an integrative process of design, implementation, monitoring, estimation, and adjustment of the support system with the aim of achieving just-in-time availability of support elements in an integrated mode. The goal of SA is to enable optimum system performance at minimum life cycle cost. SA includes the entire life cycle of the system, whereas the support element integration has been accomplished with the help of modern information and telecommunication technology. In the United States, the field of supportability analysis is regulated by the MIL-HDBK-502 ("Acquisition Logistics Handbook") and MIL-PRF-49506 ("Logistics Management Information") standards. In the context of supportability analysis, it is necessary to perform two complementary procedures: supportability analysis records, and supportability analysis reports.

The supportability analysis records procedure is a system in the form of a common relational database that is used to recognise, store, and sort supportability analysis data in a logical and accessible manner. Supportability analysis reports refer to the supportability analysis report system and statements that contain and transfer data.

Concurrent engineering (CE), also known as 'simultaneous engineering' or 'integrated product development', represents an approach to the design of a product-service bundle based on information integration. It implies performing design tasks in parallel where they have previously been done sequentially. Coordinated team work by design engineers, and the continuous flow of information between all functional departments that influence the lifecycle of product-service bundles, are necessary. This is sustained by CAx systems and helps to reduce design time and time to market. Maintenance and logistics support design should be taking place simultaneously with product design, so that changes can be made in 
the product to facilitate the manufacturing process before the final stage of product design.

Electronic data interchange (EDI) has been in use for several years, and is widely seen as B2B service. In short, EDI is an element of e-maintenance and e-commerce based on a set of standardised messages to transfer structured data from one computer application to another. EDI uses structured digital transaction sets to replace paper or verbal data exchanges. It brings a number of benefits to companies using it, such as a shorter ordering time, more accurate invoicing, and reduction of stock.

The Interactive Electronic Technical Manual (IETM) is the key component of the proposed emaintenance framework. The IETM is the paperless functional equivalent of traditional technical manuals. With the help of the IETM, maintenance engineers and technicians have access to all maintenance documents (technical manuals, maintenance work orders, supply bulletins) via desktop or notebook computers. The IETM gathers data from operating systems, and feeds the data back to improve maintenance and minimise life cycle costs.

IETMs have been divided into five classes, based on the type of display viewed by the enduser, the nature of the underlying data structures, and the specific functionality provided to users [26]. The higher the class, the more functionality the IETM provides (see Table 1). Class 1 IETMs possess limited navigation tools and utilities limited to library and reference use. Class 2 provides documents that scroll electronically, navigating through a large amount of information using hypertext. Class 3 is linearly structured documents that use hypermedia and multimedia. Class 4 IETMs are based on a hierarchically-structured database and dialogue-driven interaction. Class 5 uses artificial intelligence and expert systems for system diagnostics, and has a single viewing system for simultaneous access to multiple data sources. This class is intended to integrate future applications that are not yet ready for use.

Table 1: The functionality of IETM classes

\begin{tabular}{|l|c|c|c|c|c|}
\hline & $\begin{array}{l}\text { Class 1: } \\
\text { Electronically- } \\
\text { indexed pages }\end{array}$ & $\begin{array}{l}\text { Class 2: } \\
\text { Electronic } \\
\text { scrolling } \\
\text { documents }\end{array}$ & $\begin{array}{l}\text { Class 3: } \\
\text { Linearly- } \\
\text { structured } \\
\text { IETMs }\end{array}$ & $\begin{array}{l}\text { Class 4: } \\
\text { Hierarchically- } \\
\text { structured } \\
\text { IETMs }\end{array}$ & $\begin{array}{l}\text { Class 5: } \\
\text { Integrated } \\
\text { database }\end{array}$ \\
\hline $\begin{array}{l}\text { User selection } \\
\text { and navigation } \\
\text { aids }\end{array}$ & $\varnothing$ & $\oplus$ & $\oplus$ & $\oplus$ & $\oplus$ \\
\hline $\begin{array}{l}\text { Hyperlinks to } \\
\text { other text or } \\
\text { graphics }\end{array}$ & $\varnothing$ & $\oplus$ & $\oplus$ & $\oplus$ & $\oplus$ \\
\hline $\begin{array}{l}\text { Animation and } \\
\text { video }\end{array}$ & $\otimes$ & $\varnothing$ & $\oplus$ & $\oplus$ & $\oplus$ \\
\hline $\begin{array}{l}\text { Text and graphics } \\
\text { simultaneously } \\
\text { displayed }\end{array}$ & $\otimes$ & $\otimes$ & $\oplus$ & $\oplus$ & $\oplus$ \\
\hline $\begin{array}{l}\text { Interactive } \\
\text { maintenance aid }\end{array}$ & $\otimes$ & $\otimes$ & $\oplus$ & $\oplus$ & $\oplus$ \\
\hline $\begin{array}{l}\text { Fault tree } \\
\text { analysis }\end{array}$ & $\otimes$ & $\otimes$ & $\otimes$ & $\oplus$ & $\oplus$ \\
\hline $\begin{array}{l}\text { Access via web } \\
\text { E-learning } \\
\text { functionality }\end{array}$ & $\otimes$ & $\otimes$ & $\otimes$ & $\otimes$ & $\oplus$ \\
\hline $\begin{array}{l}\text { Expert system } \\
\text { diagnostics }\end{array}$ & $\otimes$ & $\otimes$ & $\otimes$ & $\varnothing$ & $\oplus$ \\
\hline
\end{tabular}

$$
\otimes-\text { not supported }
$$

$\varnothing$ - partially supported

$\oplus^{- \text {fully supported }}$

Maintenance departments are usually busy repairing machines. They do not have time to improve maintenance process performance within the production system. The implementtation of an e-maintenance framework implies several changes to maintenance. The main 
consequence is that the maintenance department is not overloaded with reactive tasks, but instead can carry out proactive maintenance. The second important point is that the maintenance department has more resources for maintenance improvement. In the long run, an improvement of maintenance process and maintainability will reduce the cost of a machine's life cycle. Figure 6 is a generic causal loop diagram of an e-maintenance framework. Loop A1 represents the influence of CE and SA on the level of life cycle cost (LCC). Loop A2 represents the relationship between EDI, the reduction of overmaintainance, and LCC. A3 is the loop representing the role of IETM support.

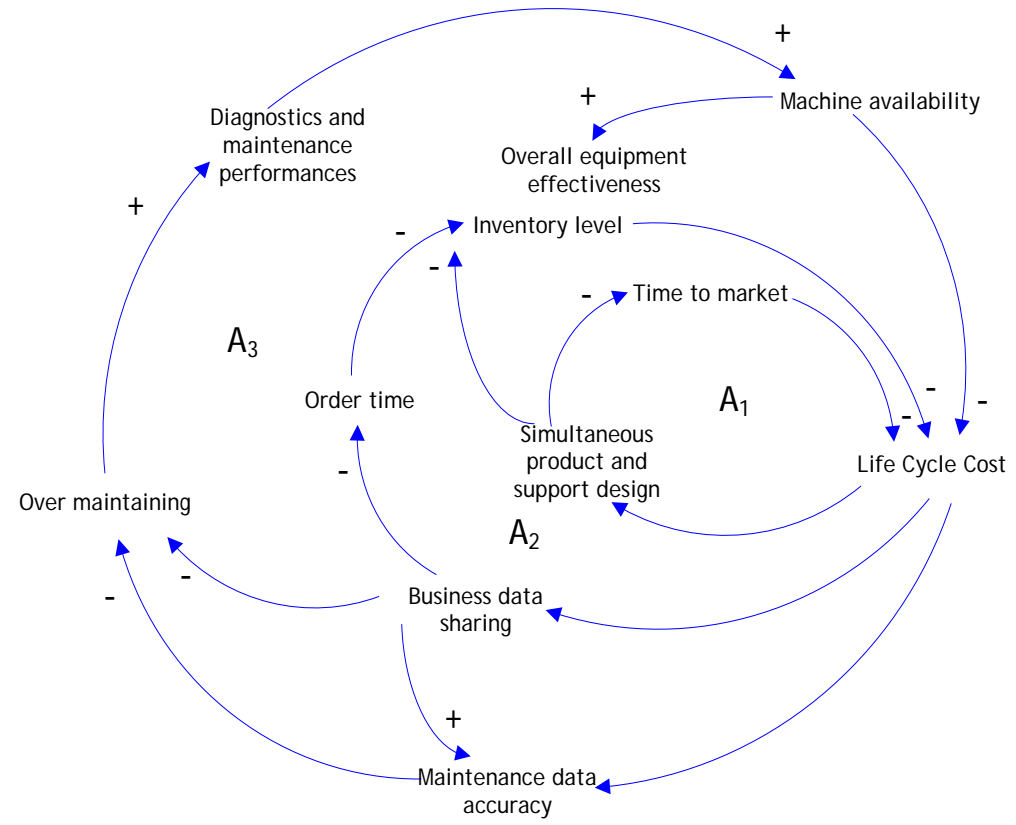

Figure 6: Causal loops of e-maintenance framework

\section{DISCUSSION}

Business processes today tend to be more coordinated, and the boundaries between them are becoming increasingly blurred, making relationships more complex. In this way, the asset management process can see the comprehensive corporate mission as a team effort, from procurement to manufacturing and logistics. Maintenance information handling, from an entire life perspective, not only makes sense: it saves time, resources, and money. Shifting maintenance to a comprehensive e-environment would be advantageous for several reasons. A digital environment allows accurate and up-to-date technical orders to be distributed electronically in the shortest possible time; there would also be a considerable saving in work-hours per person; the use of paper documents would be eliminated.

In the past decade, the importance of e-maintenance has increased because of the dynamic global environment. The direct benefits of e-maintenance are a reduced time to market and life cycle cost. E-maintenance is a strategic concept of fundamental change not only in the approach to maintenance but also in how logisticians support maintenance and logistic operations in the digital era.

The proposed e-maintenance framework is an integrated suite of engineering, supply, maintenance, and logistics application systems. It brings together several core logistic processes into one integrated data model that will provide one-time data entry and sharing of data in a digital environment. An integrated product-service database enables a more efficient just-in-time delivery of data to maintainers or to any authorised user. They will be able to access the integrated database through extensive use of web technologies. The 
basic premise of an e-maintenance framework is to create data once and use it many times. To this end, e-maintenance uses process-based integration, which refers to integrating applications developed from a business process perspective rather than a technical perspective.

A key characteristic of an e-maintenance framework is sharing maintenance and logistics information up and down the value chain. If information is shared, it can be available in real time. Maintenance staff can have on-line access to all supporting information. That data may be fed back electronically to maintenance engineers and managers to analyse and predict future maintenance and supportability requirements. The main barrier to sharing information is the complexity issue. A lot of data is collected by the ADC technology, but turning data into useful engineering information is a challenge.

The data-sharing philosophy of this e-maintenance framework is implemented by a common product-service bundle database and IETM. An IETM is about more than words and pictures on a computer screen: it ensures that good maintenance and logistic operations occur, and prevents the bad ones. IETM gives maintenance technicians a very small and portable display that interfaces with computer systems to provide an integrated source of the information needed to perform maintenance tasks. In some cases the system displays graphic instructions and provides intelligent diagnostic advice. The intelligent functionality of the IETM provides powerful interactive troubleshooting procedures for users. It also offers a technician easy and efficient ways to receive work orders, report maintenance actions, and order parts from supply lines. IETM also offers complete computer-aided training lessons and simulations.

Furthermore, IETM is an equipment-oriented effort to achieve world-class levels of machine productivity, and to ensure consistent machine performance from one working day to the next. Improving productivity involves improving the performance of both bottleneck and non-bottleneck machines in a similar way. Actually, most companies' output is limited by reliability problems in all their machines, not just by the bottleneck machines' capacity. Because of that, IETM should be applied to all equipment, not just the bottleneck. IETM also solves problems of under- and over-maintenance.

Although IETM offers many benefits, there are several negative implications, such as the additional skills in graphics and multimedia required. Other limitations are linked to cultural influences and hardware requirements. Also, the IETM community is faced with the need to enable interoperability among different IETM software packages.

Enterprises using the e-maintenance framework could benefit in many ways - for example:

- $\quad$ faster time to hypercompetitive market;

- $\quad$ reduced lead time;

- $\quad$ shortened product and support development;

- $\quad$ reduced life cycle cost;

- $\quad$ increased productivity;

- $\quad$ improved maintenance performance;

- being one step closer to total asset visibility, and so on.

To summarise, the e-maintenance framework provides a comprehensive approach to improving maintenance and logistics, which can be divided into long-term and short-term elements. In the long-term, the focus is on new equipment designs; short-term, maintenance and logistical efforts have been directed to the level of the organisation's plant.

\section{CONCLUSION}

In an era of declining resources, it is clear that e-maintenance plays a significant role in improving maintenance and logistical support performances. It deals with the core processes of an enterprise. The results described in this paper indicate that the enterprise 
can improve its maintenance process further by applying the e-maintenance framework based on the hybrid system approach.

The new e-maintenance framework is developed to coordinate maintenance and logistics data sharing between different stakeholders throughout the life cycle. In the context of sustainable business, the e-maintenance framework enables more efficient decisionmaking. The proposed e-maintenance concept takes advantage not only of the latest technologies, but also of a new collaborative concept. Shared information on a real-time basis is the key to e-maintenance excellence. Information sharing among all the members of the logistics chain can reduce waste across the entire chain.

An e-maintenance system is only as good as the information that can be retrieved from it. The e-maintenance framework provides extensive reporting capabilities that include summary and detailed reports, and easy-to-use writing tools that do not require programming knowledge.

We believe that a key issue in the success of maintenance improvement is the integration and synchronisation of logistics operations by using information technologies. Thus corporate culture should be changed to recognise that maintenance is a process that directly affects capacity - and capacity drives the profits of the corporation.

Finally, improvements in information technology are transforming the way maintenance and logistics are managed, and offer opportunity for improved control over the entire logistics system. This leads to a full optimisation of the logistics process, rather than emphasising sub-systems within the logistics organisation that generate partial optimisation and suboptimal total performance. Full-spectrum visibility and real-time supportability data management of increasingly complex technical systems will be the hallmark of further research. Continued efforts are focused on further integrating the e-maintenance concept across the entire life cycle of the technical system, so achieving the synergy inherent in a network of logistics data.

\section{ACKNOWLEDGMENT}

This research is supported by the Serbian Ministry of Science (strategic project III 47003: Infrastructure for e-learning in Serbia).

\section{REFERENCES}

[1] Swanson, L. 2001. Linking maintenance strategy to performance. International Journal of Production Economics, 70(3), 237-274.

[2] Lee, N., Djurdjanovic, D., Qui, H. \& Liao, H. 2006. Intelligent prognostics tools and emaintenance. Computers in Industry, 57(6), 476-489.

[3] Francis, R. \& Meagher, R. 2005. Implementing and performing shutdown performance improvement. Proceedings of IQPC Effective Shutdown and Turnaround Conference, Melbourne, 23-26 August 2005.

[4] Rakita, M. \& Chromjakova, F. 2001. Productivity raising approaches in the logistic production system. Management, 6(1-2), 17-24.

[5] Coyle, J., Bardi, E. \& Langley, J. 2003. The management of business logistics: A supply chain perspective. $7^{\text {th }}$ edition, USA: South-Western Thomson Learning.

[6] Salmela, E. 2004. E-business between global company and its local SME supplier network. Proceedings of Conference: LOGISTICS: Modern trends of development, Saint Petersburg, 21-22 April 2004

[7] Vasiljevic, D. \& Popadic, R. 2005. Customer satisfaction as a measure of logistics subsystem effectiveness. CD Proceedings of the 40th Annual International Logistics Conference and Exhibition SOLE 2005, "Logistics: Product and process for capability", Orlando, 16-18 August 2005.

[8] Wireman, T. 2004. Benchmarking best practices in maintenance management. $1^{\text {st }}$ edition, Industrial Press Inc, New York.

[9] Turban, E., Leidner, D., McLean, E. \& Wetherbe, J. 2006. Information technology for management: Transforming organizations in the digital economy. $5^{\text {th }}$ edition, Wiley, USA. 
[10] Kutucuogly, Y., Hamali, J., Irani, Z. \& Sharp, M. 2001. A framework with managing maintenance using performance measurement system. International J ournal of Operations and Production Management, 21(1), 173-194.

[11] Ghiani, G., Laporte, G. \& Musmanno, R. 2004. Introduction to logistics systems planning and control. $1^{\text {st }}$ edition, J ohn Wiley \& Sons Inc, United Kingdom.

[12] Vasiljevic, D. \& J ovanovic, B. 2008. Get with the change program: Strive for maintenance best practice. Industrial Engineer, 40(7), 45-48.

[13] Boyson, S., Dresner, M., Harrington, L., Corsi, T. \& Rabinovich, E. 1999. Logistics and extended enterprise: Benchmarks and best practices for the manufacturing professionals. $1^{\text {st }}$ edition, J ohn Wiley \& Sons Inc., Canada.

[14] Marquez, C. \& lung, B. 2008. A review of e-maintenance capabilities and challenges. J ournal of Systemics, Cybernetics and Informatics, 6(1), 62-66.

[15] Baldwin, R. 2000. How do you spell e-maintenance?, retrieved from www.mt-online.com.

[16] Holmerg, K., Edgar, A., Arnaiz, A., J antunen E., Mascolo J. \& Mekid S. 2010. E-maintenance. $1^{\text {st }}$ edition, Springer, United Kingdom.

[17] Verma, A., Srividya, A. and Ramesh P. 2010. A systematic approach to integrated emaintenance of large engineering plant. International Journal of Automation and Computing, 7(2), 173-179.

[18] Lung, B., Levrat, E., Marquez, A. \& Erbe, H. 2009. Conceptual framework of e-maintenance: Illustration by e-maintenance technologies and platforms. Annual Reviews in Control, 33(2), 220229.

[19] Muller, A., Marquez, A. \& Lung B. 2008. On the concept of e-maintenance: Review and current research. Reliability Engineering and System Safety, 93(8), 1165-1187.

[20] Han, T. \& Yang, B. 2006. Developing of an e-maintenance system integrating advanced techniques. Computers in Industry, 57(6), 569-580.

[21] Heider, A. \& Koronios, A. 2006. E-prognostics: A step towards e-maintenance of engineering assets. J ournal of Theoretical and Applied Electronic Commerce Research, 1(1), 42-55.

[22] Takata, S., Nimura, F., Van Houten, M., Westkämper, E., Shpitalni, M., Ceglarek, D. \& Lee, J. 2004. Maintenance: Changing role in life cycle management. Annals of the CIRPI, 53(2), 643-656.

[23] Carlisle, Y. \& McMillan, E. 2002. Thinking differently about strategy: Comparing paradigms. Proceedings of the $16^{\text {th }}$ Australian and New Zealand Academy of Management Conference, Beechworth, 4-7 December 2002.

[24] MIL-PRF-28003B 2000. Digital representation for communication of illustration data: CGM application profile, Bruxelles, NATO.

[25] Shoemaker, J. 2003. RFID use limited only by imagination. Inbound Logistics, 23(4).

[26] Jorgensen, E.J. 1994. DoD classes of electronic technical manuals, retrieved from http:// www.dt. navy. mil/ tot-shi-sys/ des-int-pro/ tec-inf-sys/ etm/ rep-pap-pre/ pdf/ CLASSES. PDF. 